\title{
Expression of antioxidant genes and photosynthetic apparatus in the soybean crop in competition with Italian ryegrass biotypes (Lolium multiflorum Lam.)
}

\author{
Daiane de Pinho Benemann ${ }^{1}$, Joanei Cechin ${ }^{1 *}$, Dirceu Agostinetto ${ }^{1}$, Leandro Vargas ${ }^{2}$ \\ ${ }^{1}$ Department of Crop Protection, Federal University of Pelotas, PO Box 354, Capão do Leão -RS, Brazil, Zip Code \\ 96010-900 \\ ${ }^{2}$ Researcher of Embrapa Wheat, Department of Weed Science, BR $285 \mathrm{Km}$ 174, PO Box 451, Passo Fundo-RS, Brazil, \\ Zip Code 99001-970
}

\author{
*Corresponding author: joaneicechin@yahoo.com.br
}

Abstract

Crop-weed competition induces stress in plants causing physiological changes which can be evaluated using the RT-qPCR technique. The aim of this study was to evaluate the stability of candidate reference genes and measure the relative gene expression of antioxidant enzymes and components of the photosynthetic apparatus in soybean in competition with glyphosate-susceptible and resistant Italian ryegrass (Lolium multiflorum Lam.). The experiment was carried out in a greenhouse using replacement series between soybean and Italian ryegrass biotypes. In this study, candidate reference genes were evaluated for use as controls in RTqPCR to quantify gene expression. An evaluation was made of genes that encode catalase, ascorbate peroxidase, superoxide dismutase, chlorophyll a/b, phytochrome A and cytochrome P450 at 50 days after emergence of the soybean. The SKIP and GAPDH genes were the most stable for soybean and Italian ryegrass, respectively. The soybean subjected to the interspecific competition with the glyphosate-resistant Italian ryegrass biotype showed an increase in superoxide dismutase gene expression. The catalase and cytochrome P450 genes were up-regulated in the susceptible biotype while the other genes were down-regulated. However, the soybean crop under interspecific competition with glyphosate-resistant biotye showed as up-regulated for all the genes evaluated. For the photosynthetic apparatus, cytochrome P450 gene was up-regulated under intraspecific competition on both Italian ryegrass biotypes, while the phytochrome A was up-regulated only in the resistant biotype. Thus, the increase in genes investigated represents a potential tool for the genetic improvement of plants to enhance their competitive capacity.

Keywords: Antioxidant enzymes; Candidate reference genes; Plant competition; Physiological changes.

Abbreviations: ANOVA_ analysis of variance; CT_ Threshold cycle; EPSPs_ 5-enolypyruvylshikimate-3-phosphate synthase; GmAPX1_ascorbate peroxidase-1; GmCAT4_catalase-4; GmMnSOD_manganese/superoxide dismutase; GmphyA_phytochrome

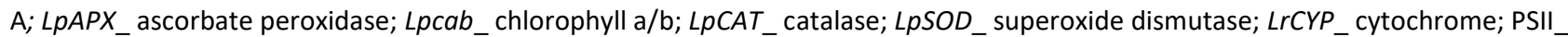
photosystem II.; ROS_reactive oxygen species; RT-qPCR_ Real time quantitative polymerase chain reaction.

\section{Introduction}

Soybean [Glycine $\max ($ L.) Merr.], long considered Brazil's main crop, can be strongly affected by weed competition. In cropping systems, chemical control is essential for weed management and has been favored by the introduction of Roundup Ready ${ }^{\circ}$ soybean, combining low cost, broadspectrum weed control and high efficacy (Duke, 2015). Glyphosate (N-phosphonomethyl-glycine) is one herbicide absorbed through foliage and translocated to the chloroplasts which inhibits the EPSP enzyme, affecting the biosynthesis of aromatic amino acids causing plant death (Steinrücken and Amrhein, 1980). However, repeated use of this herbicide to control weed resulted in the selection of Italian ryegrass (Lolium multiflorum) resistant biotypes, which can cause damage in soybean even in low density (Vargas and Roman, 2005).

Studies using the replacement series are models broadly utilized to estimate the competition between plants. The model includes constant plant density with a uniform spatial arrangement in which a portion of plants are placed in monoculture and/or in a mixture using different species/biotypes to determine the most competitive as well as the plant-to-plant interactions (Swanton et al., 2015). Thus, the yield versus proportion response of pure stands as well as mixtures are used to evaluate the interspecific (between different species/biotypes) and intraspecific (same species/biotype) competition. During the initial development, the competition between soybean and Italian ryegrass for resources such as water, nutrients and light is considered a significant threat to yield and causes irreversible damage even when stress is removed (Ricce et al., 2011). The limitation of resources during development depends on the infesting population and the phenological stage of the plant which will cause changes in the relationship of red light ( $R=630 \mathrm{~nm}$ ) to far red light (FR $\lambda=730 \mathrm{~nm}$ ) due to competition between neighboring plants (Page et al., 2010; Mazza and Ballaré, 2015). 
Light quality changes due to plant competition are detected by phytochrome photoreceptors and may cause physiological changes and differential responses to gene expression levels in response to escape shading (Le et al., 2012; Mckenzie-Gopsill et al., 2016). The evaluation of competition and secondary effects of crop-weed competition, which is important to determining the physiological responses to stress tolerance, can be analyzed through gene expression (Horvath et al., 2015). Certain types of stress such as water deficit, heat, and herbicide spraying induce the production of ROS as hydrogen peroxide $\left(\mathrm{H}_{2} \mathrm{O}_{2}\right)$, superoxide $\left(\mathrm{O}^{\circ}\right)$, hydroxyl radical $\left(\mathrm{OH}^{\circ}\right)$, and singlet oxygen $\left({ }^{1} \mathrm{O}_{2}\right)$, and trigger increases in gene expression of antioxidant enzymes to protect against oxidative stress (MckenzieGopsill et al., 2016; Choudhury et al., 2017). Previous studies have reported genetically engineered plants with overexpressing antioxidant genes, demonstrating higher levels of the ROS scavenging enzymes and better stress tolerance (Badawi et al., 2004; Tseng et al., 2007).

Thus, knowledge of antioxidant gene activity provides a certain degree of tolerance which can be useful to understanding tolerance and breeding tolerant cultivars (Mhadhbi et al., 2011). However, gene expression evaluated by the RT-qPCR technique requires the use of reference genes to minimize the effect of the amount of RNA and reverse transcription efficiency (Bustin, 2002). The most used reference genes are $\beta$-actin $(A C T)$, glyceral-dehyde-3phosphate dehydrogenase (GAPDH), 185 ribossomal RNA, polyubiquitin $(U B Q)$, ubiquitin conjugating enzyme $(U B C)$, elongation factor 1-A (EF1A), cyclophylin (CYP), metallo protease (MTP), SKIP/Ask-Interacting Protein (SKIP) and tubulin (TUB) among others, which must remain stable under different environmental conditions (Ma et al., 2013). The mechanism of tolerance induced by oxidative stress as a tool of potential selection to improve plant tolerance has not yet been thoroughly investigated in Roundup Ready soybean and glyphosate-susceptible and resistant biotypes of Italian ryegrass under inter and intraspecific competition. The results may explain the stress response and contribute to our knowledge of adaptation to inter and intraspecific competition at the gene expression level. Therefore, the aim of this study was to evaluate the stability of candidate reference genes and measure the relative gene expression in Roundup Ready soybean and glyphosate-susceptible and resistant biotypes of Italian ryegrass in inter and intraspecific competition.

\section{Results and discussion}

\section{Efficiency and stability of reference genes}

The more suitable dilution of samples for amplification was 1:5 which was later used to validate the target genes. Efficiencies ranged from 1.94 to 2.18 for the TUB4 and MTP genes in soybean crop, and from 1.60 to 2.20 for HIST and $18 \mathrm{~s}$ in Italian ryegrass (Table 1 ).

Based on the Cq values, nine and four of the genes tested showed differential expression levels in soybean and Italian ryegrass, respectively. TUA5 and 185 genes were upregulated with lowest mean of the Cq values of 25.12 and 13.33 for soybean and Italian ryegrass, respectively (Fig. 1). Other studies report the use of TUA5 and 185 such as candidate reference genes more stable in plants under different stress for quantification in RT-qPCR (Chi et al., 2012; Ma et al., 2013).
According to NormFinder, which was used to analyze the variance intra and intergroups, the candidate genes with low $M$ value in soybean were SKIP $(\mathrm{M}=0.33)$ and $A C T 2 / 7$ $(\mathrm{M}=0.35)$ and, Italian ryegrass which was $G A P D H$ gene with $M=1.10$ (Fig. 2A and $3 A$ ). However, the least stable gene for the species evaluated was TUB4 with an $M$ value of 1.12 and 3.09, respectively (Fig. 1A). TUB4 is a structural $\beta$-tubulin of the cytoskeleton that is involved in various cellular functions and is unstable, depending on the type of stress and species used for normalization (Hu et al., 2009). By the BestKeeper the reference genes MTP, Fbox, TUA5 and 605 were identified as the most stable for soybean ( $M$ value $<1$ ) (Fig. $2 \mathrm{~B})$ and the gene $60 \mathrm{~S}(\mathrm{M}=1)$ for Italian ryegrass (Fig. 3B).

For the $\Delta C$ comparative method, SKIP $(\mathrm{M}=0.76)$ and ACT2/7 $(M=0.77)$ were the most stable genes for soybean and showed similar stability results with NormFinder for all candidate reference genes (Fig. 2C). In Italian ryegrass, GAPDH $(\mathrm{M}=1.50)$ was considered the most stable gene while TUB4 (M=3.41) was the least stable, with stability resembling that found using NormFinder (Fig. 2C). The M values calculated by geNorm software on eight candidate genes for normalization in soybean under competition with Italian ryegrass demonstrate that the EFL1B and SKIP $(\mathrm{M}=0.33)$ were the more stable genes while TUB4 $(M=0.94)$ was not stable (Fig. 2D).

In Italian ryegrass, the 605 and $18 s$ genes $(M=0.65$ and $M=0.67$, respectively) were less stable than TUB4 and considered the lowest stable gene ( $M=1.33$ ) (Fig. 3D). Similar studies demonstrated significant variation between reference genes in plants under stress (Chi et al., 2012; Ma et al., 2013). For example, as regards water deficit, the best candidate genes in soybean were TUB4, TUA5 and EF1A while the most stable gene to virus infection was EF1B (Ma et al. 2013). However, for rice plants competing with red rice, the $U B C-E 2$ gene was the most stable and $18 s$ the least (Benemann et al., 2017).

The general ranking of the best genes for normalization was obtained through the combination of each algorithm tested (Chen et al., 2011). These results indicated SKIP ( $M=1.5)$ and GAPDH $(M=1.37)$ were the most stable genes for soybean and Italian ryegrass, respectively (Fig. $4 \mathrm{~A}$ and $4 \mathrm{~B}$ ). This is the first study to validate candidate reference genes for gene expression analysis through RT-qPCR for soybean and Italian ryegrass in competition. In recent research studies, results have shown GAPDH and SKIP are the most stable reference genes and, therefore, considered in the top five for use in studies which investigate abiotic and biotic stress (Yang et al., 2014). GAPDH is a key-enzyme of the glycolytic pathway involved in conversion of the glyceraldehyde-3-phosphate with up-regulated expression in plants under abiotic stress (Zeng et al., 2016). Nevertheless, SKIP is a conserved gene of the spliceosome which acts in the first and second steps of pre-mRNA splicing and in the signaling of environmental stresses (Wang et al., 2012; Feng et al., 2015).

Reference genes are an important step in the use of RT-qPCR due to their higher level of relative expression for most cells and stability in a set of samples of interest where the expression level can be compared with target genes (Andersen et al., 2004). However, a small number of reference genes have been validated in weeds because there is limited information about the genomes of these plants. 


\section{Minimum number of reference genes}

Using the geNorm program, the optimal number of genes for validating gene expression in soybean and Italian ryegrass biotypes under competition was determined as a function of the variation in pairs $\left(V_{n} / V_{n+1}\right)$ between two factors of sequential normalization where, for the higher $V$ value, the gene inclusion subsequent for normalization has a significant effect (Vandesompele et al., 2002). Considering the cut-off point established $(\mathrm{V} \leq 0.15)$, our results suggested the use of only one reference gene for normalization of gene expression of plants in competition using foliar tissues with $V_{2 / 3}=0.11$ for both species (Fig. $5 A$ and $5 B$ ).

Gene expression of soybean and susceptible and glyphosate-resistant Italian ryegrass

The effects of inter and intraspecific competition on gene expression in soybean (GmSOD, GmCAT4, GmAPX1, Gmcab3, GmCYP and GmphyA) in susceptible and resistant Italian ryegrass ( $L p C A T, L p S O D, L p A P X, L p c a b, L r C Y P$ and $L p p h y A$ ) demonstrated a differential expression, mainly in glyphosate-resistant Italian ryegrass for interspecific competition (Fig. 6 to 8). In plants, different types of stress can cause ROS formation, considered as sensors of metabolic regulation and gene transcription (Choudhur et al., 2017).

\section{Gene expression of oxidative stress in soybean and Italian ryegrass}

The results of interspecific competition between soybean and glyphosate-susceptible and glyphosate-resistant Italian ryegrass demonstrated down-regulation of the catalase-4 (GmCAT4) and ascorbate peroxidase-1 (GmAPX1) genes, except in the case of manganese/superoxide dismutase $(G m M n S O D)$ which was up-regulated $(R E=1.56)$ in competition with glyphosate-resistant Italian ryegrass compared to monoculture soybean ( $R E=1.0)$, differing statistically from the other treatments. For the GmCAT4 gene, there was a statistical difference between monoculture soybean and interspecific competition with Italian ryegrass but for the GmAPX1 gene no significant difference was found (Fig. 6A).

As regards glyphosate-susceptible Italian ryegrass under interspecific competition, catalase ( $\angle P C A T)$ was up-regulated $(\mathrm{RE}=1.09)$ while superoxide dismutase $(\angle p S O D)$ with $\mathrm{RE}=0.85$ and ascorbate peroxidase $(\angle P A P X)$ with $\mathrm{RE}=0.61$ were downregulated (Fig. 7A). All the responsive genes for oxidative stress in the glyphosate-resistant biotype showed upregulation when under interspecific competition differing statistically from monoculture soybean (control) (Fig. 7B). The presence of neighboring plants causes changes in the light quality usually inducing the expression of oxidative stress genes and can generate negative effects on crop development, depending on the plant phenological stage (Mckenzie-Gopsill et al., 2016). ROS are signaling molecules of high redox with the lipids involved in the formation of cell membranes which can cause peroxidation and irreversible damage (Mittler, 2017).

The increase of ROS in plants under stress has been reported as a signaling pathway for activation of the defense systems due to the positive regulation of antioxidant enzymes such as SOD, CAT and APX to prevent damage on cell membranes, DNA, RNA and proteins (Mittler, 2017). A number of studies reported the up-regulation of SOD for hydric deficit tolerance in corn plants acting as a cell defense mechanism against $\mathrm{H}_{2} \mathrm{O}_{2}$ formation and free radicals and can thus be used for indirect selection for oxidative stress tolerance (Zaefyzadeh et al., 2009). Other researchers have identified CAT as an enzyme involved in the elimination of the $\mathrm{H}_{2} \mathrm{O}_{2}$ produced during photorespiration and $\beta$-oxidation of fatty acids, which is an activity regulated under higher concentrations of $\mathrm{H}_{2} \mathrm{O}_{2}$ to maintain non-toxic basal levels (Choudhur et al., 2017). Similarly, APX is a heme-protein of the peroxidase superfamily with various isoforms found in the cytosol, mitochondria, peroxisomes, chloroplasts and cell wall that is involved in the detoxification of $\mathrm{H}_{2} \mathrm{O}_{2}$ (Bhatt and Tripathi, 2011). However, the knowledge of differential gene expression for plants under competition is still limited and may be an innovative tool to provide competitive advantage to crops.

\section{Gene expression of the photosynthetic apparatus in soybean and Italian ryegrass}

Soybean under interspecific competition with both Italian ryegrass biotypes demonstrated down-regulation for all genes tested. However, only chlorophyll a/b (Gmcab3) showed statistical differences between the inter and intraspecific competition while phytochrome A (GmphyA) and cytochrome P450 monooxygenase - CYP82C1p (GmCYP) did not differ statistically from the other treatments evaluated (Fig. 6B). For the susceptible biotype under interspecific competition, all genes were down-regulated compared to the control, except for cytochrome ( $\operatorname{CrCYP}$ ) which was up-regulated $(R E=2.49)$ and differed from monoculture (Fig. 7B). In susceptible biotype under intraspecific competition, only the $L r C Y P$ gene was upregulated while the phytochrome $\mathrm{A}(L p P h y A)$ and Lpcab were down-regulated (Fig. 8A). In resistant biotype, the LpPhyA and $L$ rCYP genes ( $R E=5.73$ and 2.31, respectively) were up-regulated and differed from the control ( $R E=1.00)$, although no statistical difference was observed for monoculture in chlorophyll a/b (Lpcab) with $\mathrm{RE}=1.44$ (Fig. $8 \mathrm{~B})$. The light-harvesting chlorophyll $\mathrm{a} / \mathrm{b}$ binding-proteins (LHCB or CAB) are involved in light absorption by PSII and, normally, is complexed with chlorophyll and xanthophyll in the antenna complex (Jansson, 1994). The expression of CAB can be regulated by several environmental factors during the development of plants, especially by light, oxidative stress and regressive signals of chloroplasts, being considered the main modular mechanism of chloroplasts (Feng et al., 2014). According with Nohatto et al. (2016) studying genes involved in light capture realized that OsCRY2 exhibited increased expression for cultivated rice, only when the culture was placed under interspecific competition and OsPIL1 and OsCAB1 showed increased expression in wild rice under intraspecific and interspecific competition, respectively. The changes in relation to $\mathrm{R} / \mathrm{FR}$ are detected by photoreceptors in plants and cause an important adaptive response (shade avoidance syndrome), affecting the apical dominance and resource partitioning between root and shoot as well as causing elongation of the stem (Ballaré, 2014). Our results demonstrated that only the glyphosate-resistant biotype showed competitive advantage in light absorption through CAB and phyA.

The phyA and phyB are directly involved in light perception, and interact with transcription factors, affecting the stability of jasmonate, and are responsible for the activation of stress responses at the transcriptional level (Ballaré, 2014). Recent researches on the light signal transduction pathway have 
Table 1. Candidate reference genes for normalization of RT-qPCR in soybean and Italian ryegrass in competition.

\begin{tabular}{|c|c|c|c|}
\hline \multicolumn{4}{|l|}{ Soybean } \\
\hline Gene & Primer sequences $\left(5^{\prime} \rightarrow 3^{\prime}\right)^{1}$ & Efficiency & Reference \\
\hline \multirow{2}{*}{ ACT2/7 } & F - CTTCCCTCAGCACCTTCCAA & \multirow{2}{*}{2.13} & \multirow{2}{*}{ Jian et al. (2008) } \\
\hline & R - GGTCCAGCTTTTCACACTCCAT & & \\
\hline \multirow{2}{*}{ ACT11 } & F - ATCTTGACTGAGCGTGGTTATTCC & \multirow{2}{*}{2.04} & \multirow{2}{*}{ Hu et al. (2009) } \\
\hline & R - GCTGGTCCTGGCTGTCTCC & & \\
\hline \multirow{2}{*}{ ELF1B } & F - GTTGAAAAGCCAGGGGACA & \multirow{2}{*}{2.09} & \multirow{2}{*}{ Jian et al. (2008) } \\
\hline & R - TCTTACCCCTTGAGCGTGG & & \\
\hline \multirow{2}{*}{ SKIP } & F - GAGCCCAAGACATTGCGAGAG & \multirow{2}{*}{2.20} & \multirow{2}{*}{ Hu et al. (2009) } \\
\hline & R - CGGAAGCGGAAGAACTGAACC & & \\
\hline \multirow{2}{*}{ MTP } & F - CGCTCCAAGTGCTCCTCATTAG & \multirow{2}{*}{2.18} & \multirow{2}{*}{ Hu et al. (2009) } \\
\hline & R - TGAAGTAACCGACGCCAACG & & \\
\hline \multirow{2}{*}{ Fbox } & F - AGATAGGGAAATTGTGCAGGT & \multirow{2}{*}{1.98} & \multirow{2}{*}{ Le et al. (2012) } \\
\hline & R - CTAATGGCAATTGCAGCTCTC & & \\
\hline \multirow{2}{*}{$60 \mathrm{~S}$} & F - AAAGTGGACCAAGGCATATCGTCG & \multirow{2}{*}{2.11} & \multirow{2}{*}{ Le et al. (2012) } \\
\hline & R - TCAGGACATTCTCCGCAAGATTCC & & \\
\hline \multirow{2}{*}{ TUA5 } & F - TGCCACCATCAAGACTAAGAGG & \multirow{2}{*}{1.87} & \multirow{2}{*}{ Hu et al. (2009) } \\
\hline & R - ACCACCAGGAACAACAGAAGG & & \\
\hline \multirow{2}{*}{ TUB4 } & F - GGCGTCCACATTCATTGGA & \multirow{2}{*}{1.94} & Hu et al (2009) \\
\hline & R - CCGGTGTACCAATGCAAGAA & & huet al. (<00y) \\
\hline Italian ry & & & \\
\hline $18 \mathrm{~s}$ & F- AACACTTCACCGGACCATTCA & 220 & 7hang and Hu (2009) \\
\hline 108 & R- CGTCCCTGCCCTTTGTACAC & 2.20 & Lnang anta nu (ZUOY) \\
\hline & F- GGATCTCACGGACTCCCTCAT & & \\
\hline$A C T$ & R- CGGCTGAGGTTGTGAAGGA & 1.70 & Mohammadi et al. (2007) \\
\hline HIST & F- GTCCGGACCGATCGGATT & 160 & Mohammadi et al (2007) \\
\hline MIST & R- TCATTTAGAAGCAGGGATATGTCTTC & 1.00 & IVIOnammadi el al. (<00/) \\
\hline GAPDH & F-AACTGTTCATGCCATCACTGCCAC & 206 & Wan et al (2010) \\
\hline & R- AGGACATACCAGTGAGCTTGCCAT & & (5) \\
\hline Cyclo & F- CAAGCCGCTGCACTACAAGG & 1.65 & Crismani et al. (2006) \\
\hline Cycio & R- AGGGGACGGTGCAGATGAA & 1.05 & (2) \\
\hline 605 & F- CAAGGAGTACCGTGACAC & 1.91 & Paolacci et al. (2009) \\
\hline & R- GCGGGAACTTGATCTTCG & & \\
\hline$A D P$ & F- GCTCTCCAACAACATTGCCAAC & 1.70 & Paolacci et al. (2009) \\
\hline & R- GCTTCTGCCTGTCACATACGC & & \\
\hline$C D C P$ & F- CAAATACGCCATCAGGGAGAACATC & 1.68 & Paolacci et al. (2009) \\
\hline & R- CGCTGCCGAAACCACGAGAC & & \\
\hline TUA5 & F- GGCTTGTGTCTCAGGTTATCTCATC & 2.09 & Clarke and Rahman (2005) \\
\hline & R- CATGGAGGATGGCTCGAAGG & & \\
\hline eEF1As & F- CCGTTTTGTCGAGTTTGGT & 2.19 & Lee et al. (2010) \\
\hline & R- AGCAACTGTAACCGAACATAGC & & \\
\hline
\end{tabular}

${ }^{1}$ Forward (F) and Reverse (R) primers.

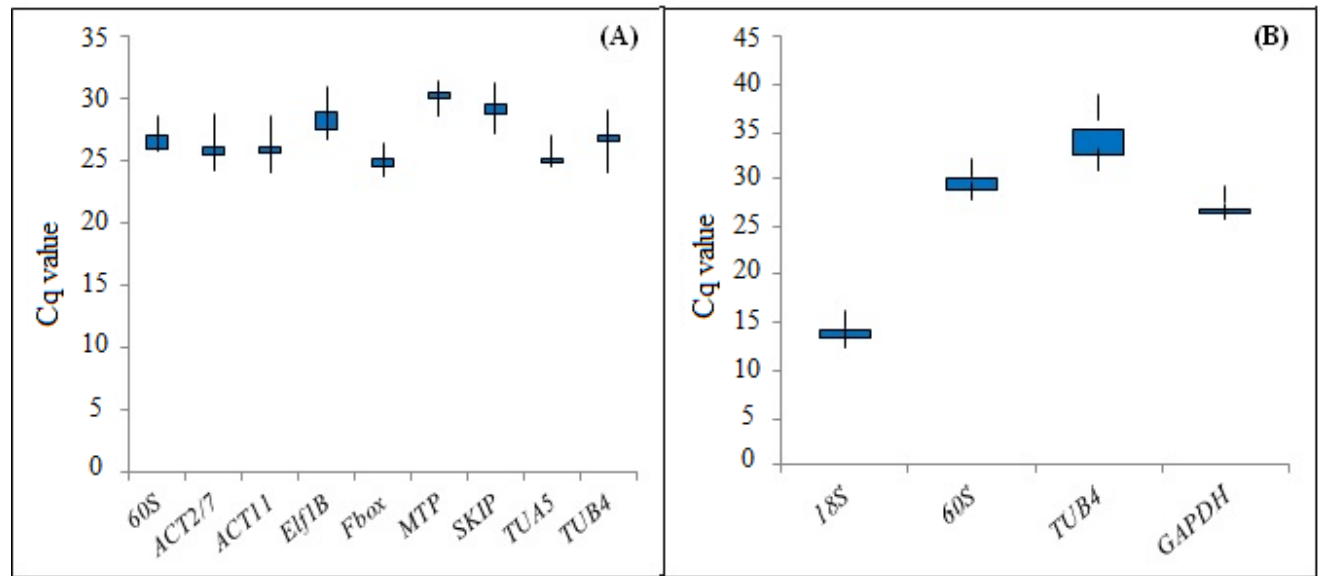

Fig 1. Quantification cycle (Cq) of the candidate reference genes in soybean (A) and Italian ryegrass (B) samples in competition. The box indicates the mean and the whiskers represent the minimum and maximum values. 
Table 2. Target genes for RT-qPCR in soybean and Italian ryegrass plants in competition.

\begin{tabular}{|c|c|c|c|}
\hline \multicolumn{4}{|l|}{ Soybean } \\
\hline Gene & Primer sequences $\left(5^{\prime} \rightarrow 3^{\prime}\right)^{1}$ & Efficiency & Reference $^{2}$ \\
\hline \multirow{2}{*}{ GmMnSOD } & F- AGCAGACACTTGAGTTTCAC & \multirow{2}{*}{2.30} & Accession: \\
\hline & R- CACCCTTATTGTATGATGTGAC & & M64267 \\
\hline \multirow{2}{*}{ GmAPX1 } & F- AAGTCTTACCCAACTGTGAG & \multirow{2}{*}{2.09} & Accession: \\
\hline & R- CCAAACGGAGCATTAGAGGA & & NM 001250856 \\
\hline \multirow{2}{*}{ GmCAT4 } & F- CGCCTTCAATTCTCCCTTCTG & \multirow{2}{*}{1.80} & Accession: \\
\hline & R- TTCTCCACAAGATGATAATCCTCC & & NM_001250642 \\
\hline \multirow{2}{*}{ GmCYP } & F- GGAAGGACAGGAAGGTGGAA & \multirow{2}{*}{2.00} & Accession: \\
\hline & R- CCAGCAGGAATGTGATAGCCA & & AF022461 \\
\hline \multirow{2}{*}{ Gmcab3 } & F- CAGATATTCAGTGAGGGTGGG & \multirow{2}{*}{2.03} & Accession: \\
\hline & R- CTGGATAGATTGGGTCAGTCAC & & NM_001248354 \\
\hline \multirow{2}{*}{ GmphyA } & F- AATATAGGAGGAATGAGTGGGT & \multirow{2}{*}{1.19} & Accession \\
\hline & R-ATCTTGGTTGTGAATGCTTGTG & & EU428746 \\
\hline \multicolumn{4}{|c|}{ Italian ryegrass } \\
\hline \multirow{2}{*}{$\angle p S O D$} & F- GTTGACAAGCATATCCCCCTTAC & \multirow{2}{*}{2.00} & \multirow{2}{*}{ Huang et al. (2014) } \\
\hline & R- AGTGCTCTTGCTAAGCTCATGTC & & \\
\hline \multirow{2}{*}{$\angle P A P X$} & F- AGAGGATCACGGGTCCATGCAC & \multirow{2}{*}{2.20} & \multirow{2}{*}{ Li et al. (2012) } \\
\hline & R- GATGCTAAGAGAGGGGCACCAC & & \\
\hline \multirow{2}{*}{ LpCAT } & F- GCAAGAACCACAGCCACGCCA & \multirow{2}{*}{2.20} & \multirow{2}{*}{ Li et al. (2012) } \\
\hline & R- CCTCGGGCCAGGTCTTGGT & & \\
\hline \multirow{2}{*}{$\operatorname{LrCYP}$} & F- GAGGGAAACCGAGTCAAGGA & \multirow{2}{*}{1.80} & \multirow{2}{*}{ Accession: AB097496 } \\
\hline & R- TTGTAGATCGTGTCCGTGCC & & \\
\hline \multirow{2}{*}{$L p c a b$} & F- ATTGTCGACCCTCTATACCC & \multirow{2}{*}{1.87} & \multirow{2}{*}{ Accession: JF747489 } \\
\hline & R- AGTGACGATAGCCTGAACGA & & \\
\hline \multirow{2}{*}{ LpPhyA } & F- ATGAGTGGGTTTGGGTTGTG & \multirow{2}{*}{1.99} & \multirow{2}{*}{ Accession: JU962780 } \\
\hline & R- TCTTGGTTGTGAATGCTTGTG & & \\
\hline
\end{tabular}

${ }^{1}$ Forward (F) and Reverse (R) primers; ${ }^{2}$ Accession from https://www.ncbi.nlm.nih.gov
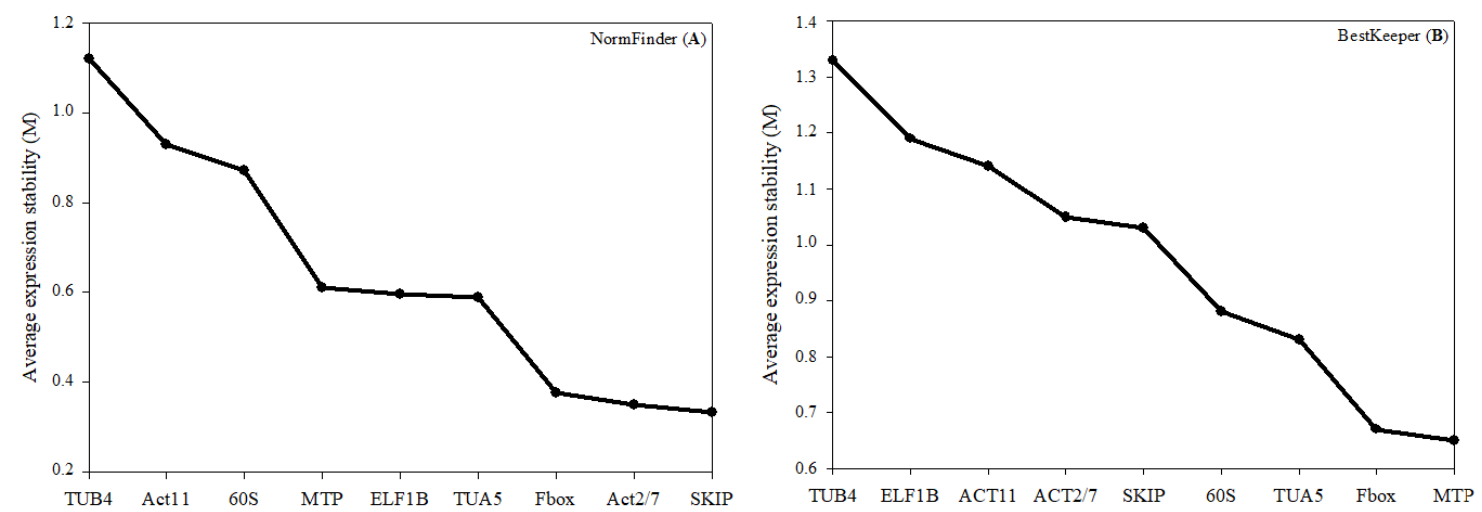

Least stable genes (:::::::::::::::::::::::::::) More stable genes

Least stable genes $\langle::::::::::::::::::::::::>$ More stable genes
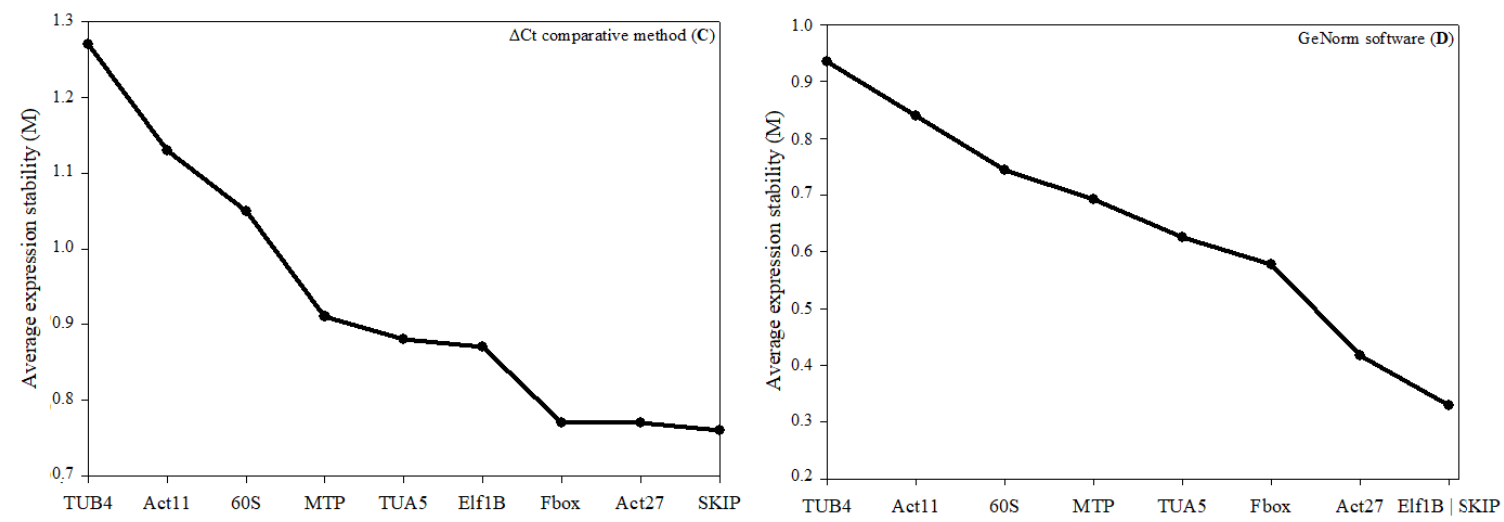

Least stable genes $\{:::::::::::::::::::::::::>$ More stable genes

Least stable genes $\langle::::::::::::::::::::::::::\rangle$ More stable genes

Fig 2. Average stability expression (M) according to the algorithm NormFinder (A), BestKeeper (B), $\Delta$ Ct comparative method (C) and GeNorm software (D) of nine candidate normalization genes in soybean competing with ryegrass glyphosate resistant and susceptible. 

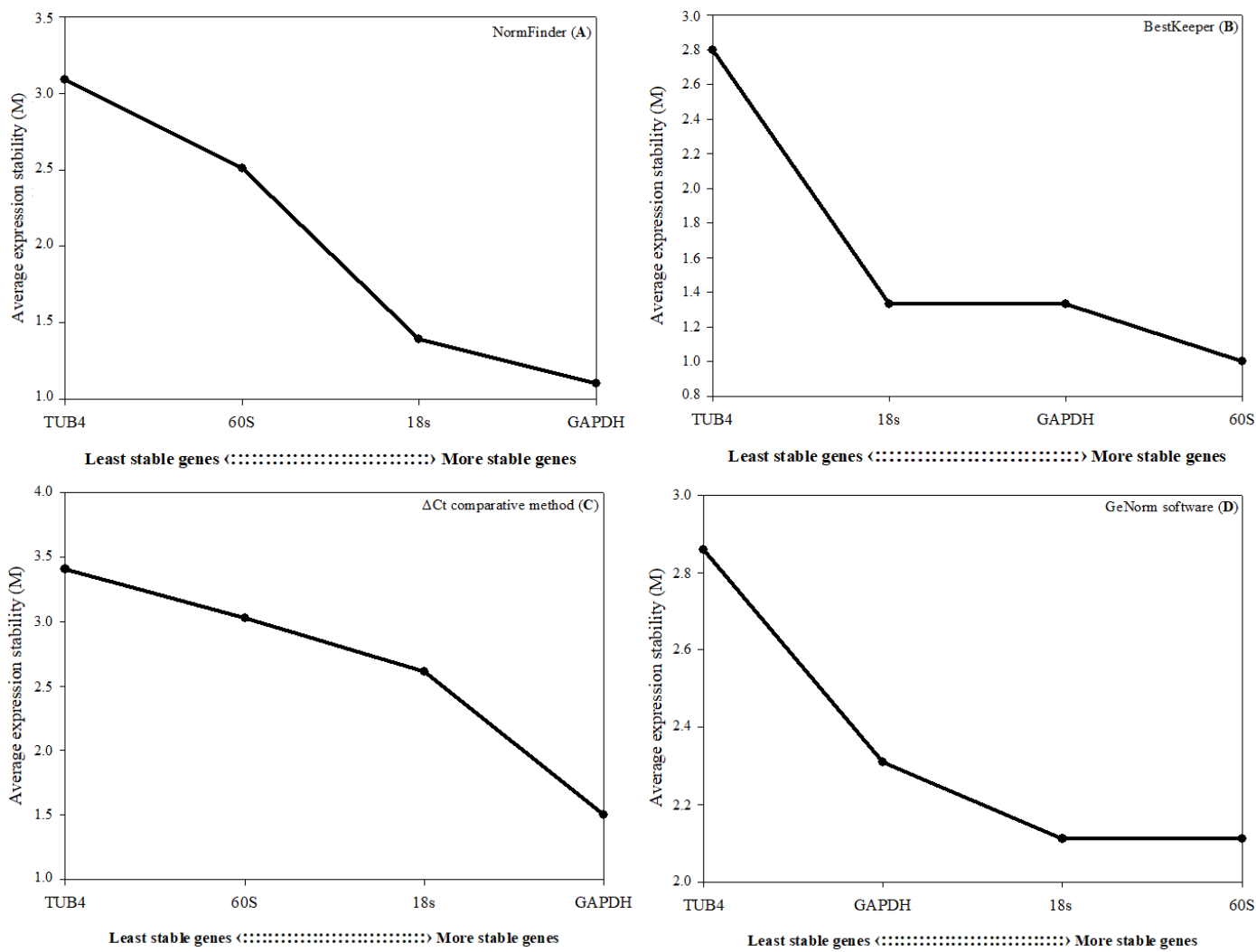

Fig 3. Average stability expression (M) according to the algorithm NormFinder (A), BestKeeper (B), $\Delta$ Ct comparative method (C) and GeNorm software (D) of four candidate normalization genes in glyphosate resistant and susceptible Italian ryegrass competing with soybean.

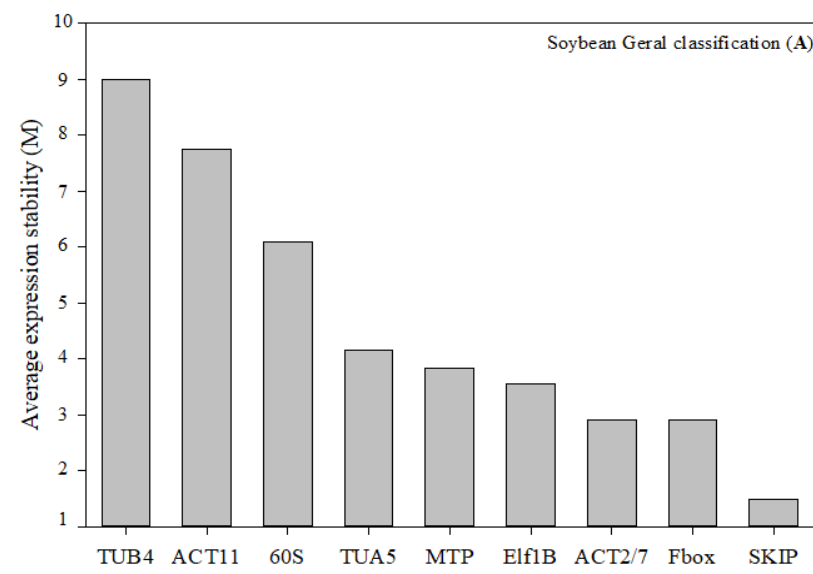

Least stable gen es $\langle::::::::::::::::::::::::>$ More stable genes

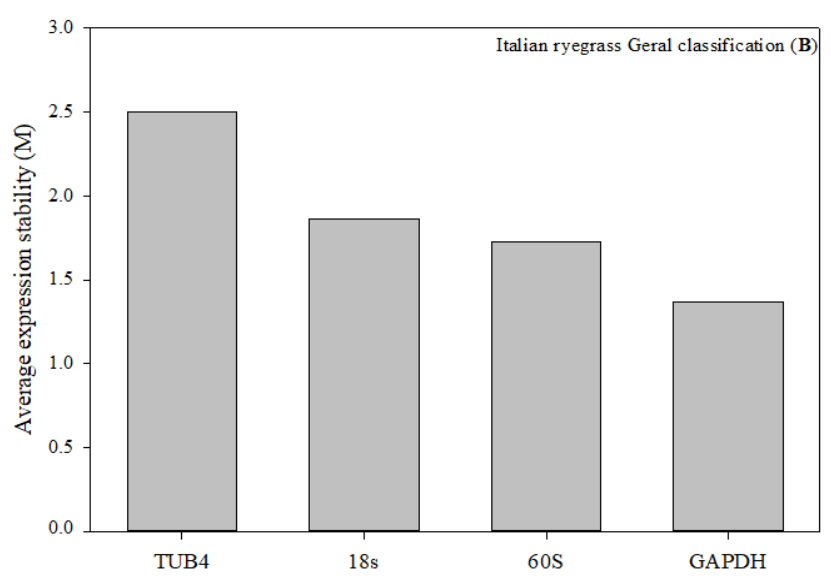

Least stable gen es $\langle:::::::::::::::::::::::::$ : More stable gen es

Fig 4. Mean expression stability (M) according to a combination of geNorm, NormFinder, BestKeeper and $\Delta$ Ct comparative method algorithms for the reference genes in soybean (A) resistant and susceptible Italian ryegrass biotypes (B) in competition. 

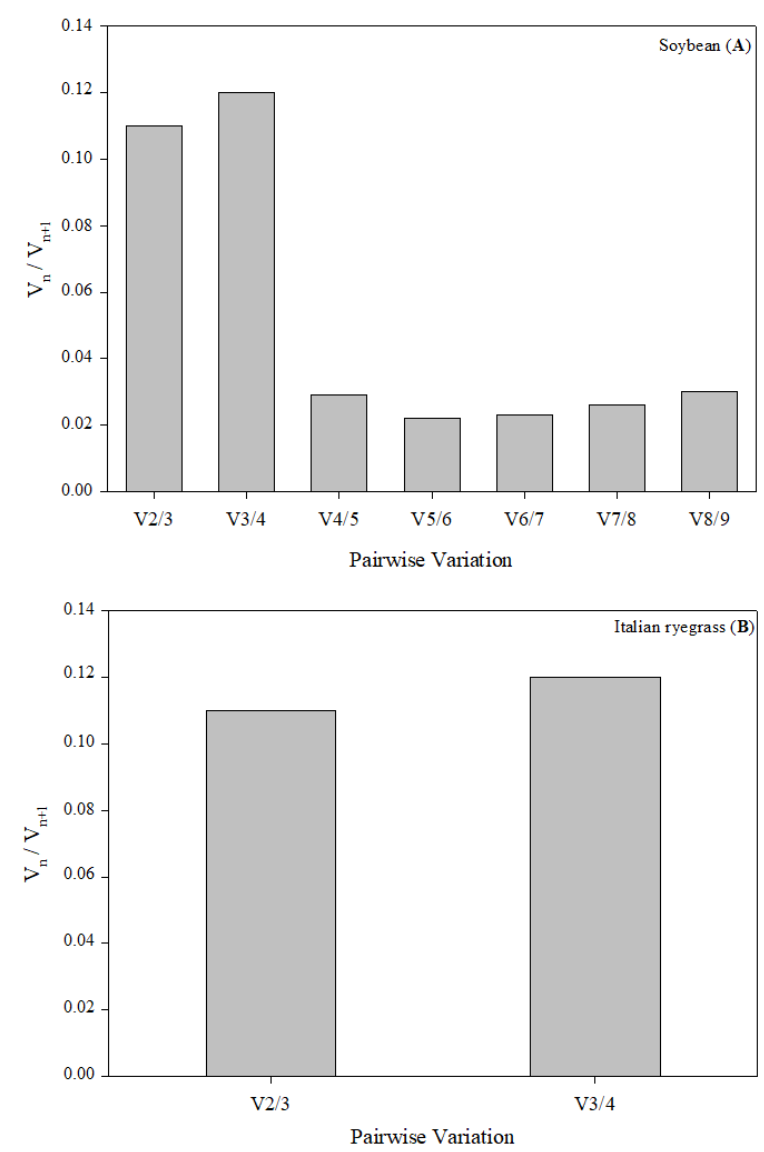

Fig 5. Variation in pairs (V) calculated by geNorm to determine the minimum number of reference genes for normalization in soybean $(\mathbf{A})$ and Italian ryegrass biotypes $(\mathbf{B})$ in competition. Value $(\mathrm{V}<0.15)$ indicates absence of more genes needed to calculate a reliable normalization factor.
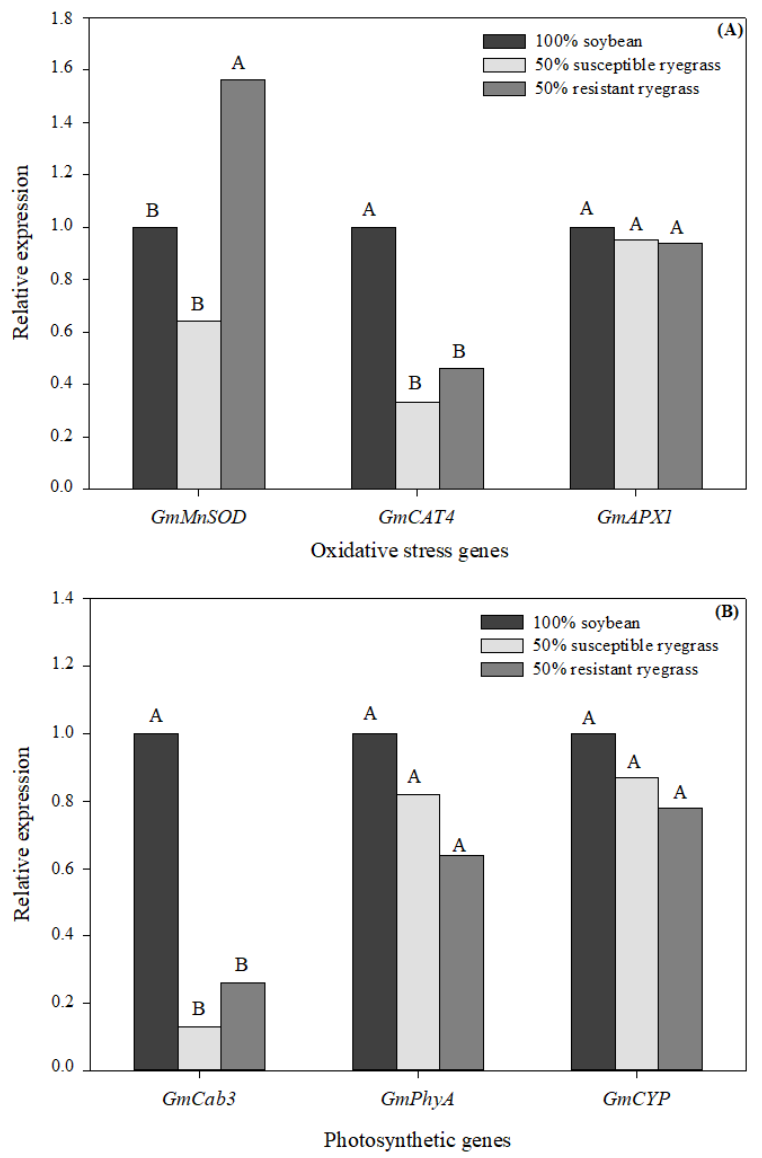

Fig 6. Relative expression of responsive genes to antioxidant enzymes (A) and target photosynthetic (B) in soybean plants in competition with susceptible and resistant Italian ryegrass biotypes. Same letter does not differ by Tukey test $(p \leq 0.05)$. 

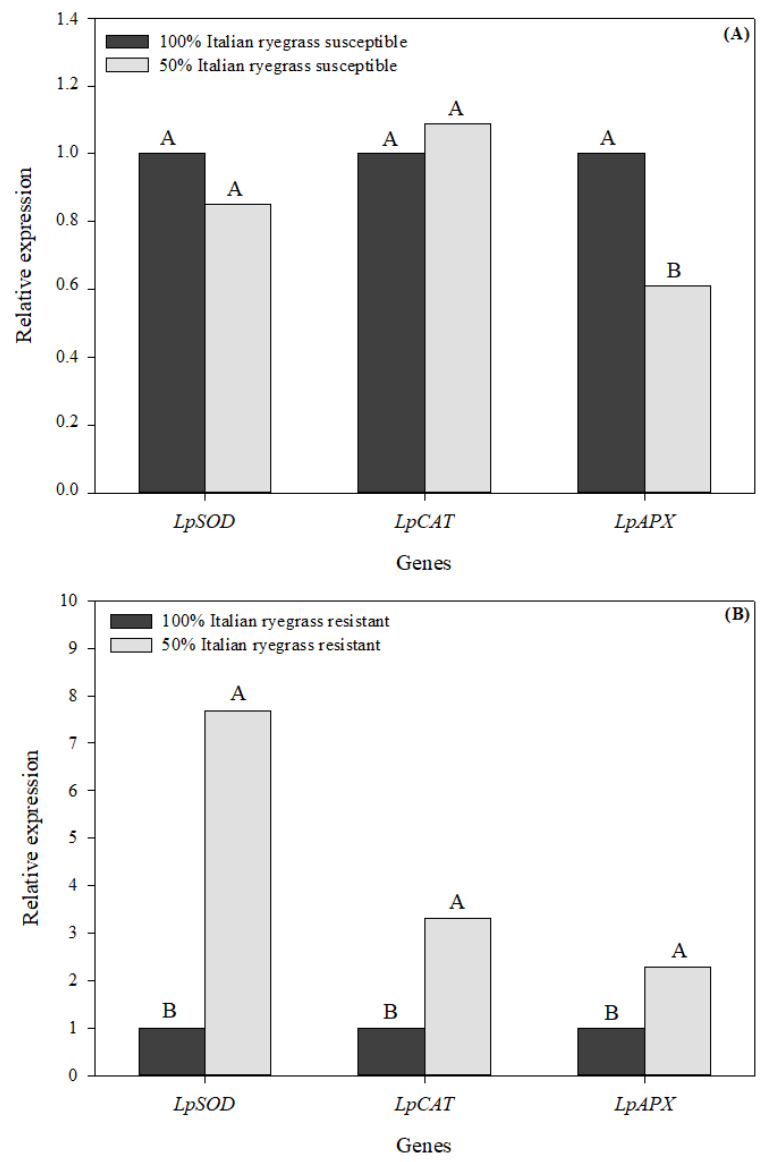

Fig 7. Relative expression of responsive genes to antioxidant enzymes in susceptible (A) and resistant (B) Italian ryegrass in intraspecific competition. Same letter does not differ by Tukey test $(p \leq 0.05)$.
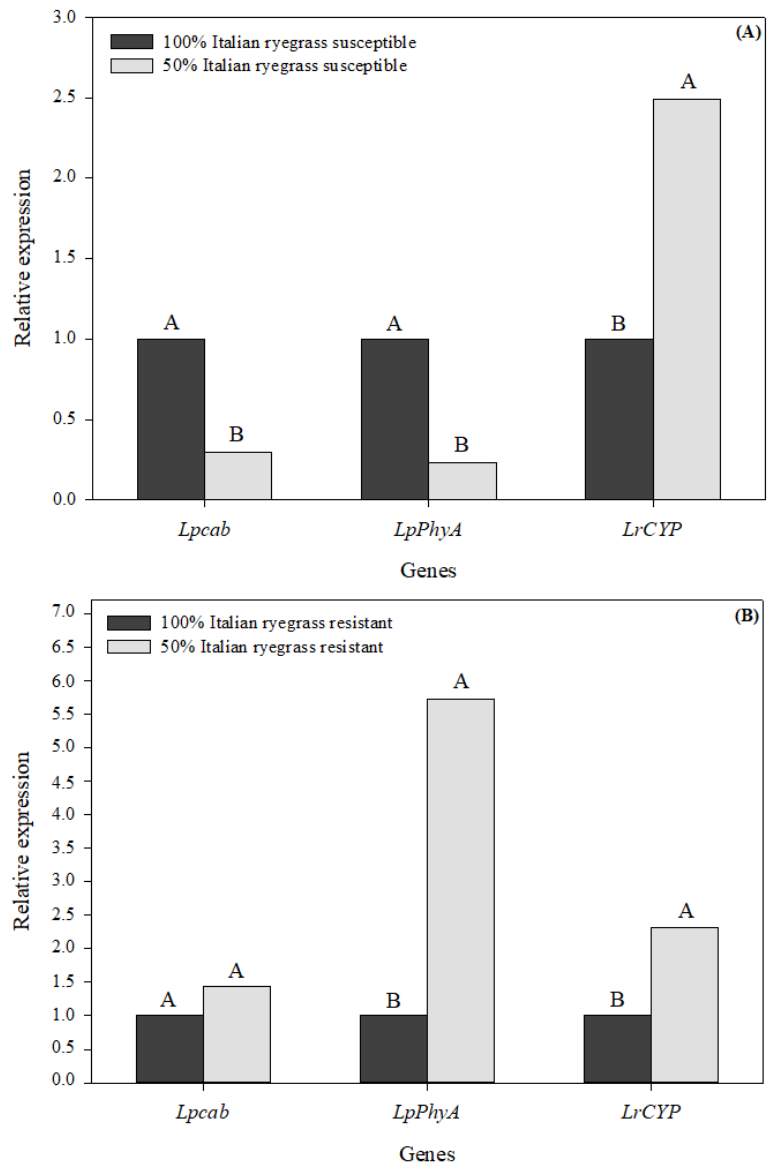

Fig 8. Relative expression of target photosynthetic genes in susceptible (A) and resistant (B) Italian ryegrass in intraspecific competition. Same letter does not differ by Tukey test $(p \leq 0.05)$. 
been the target of genetic modification, such as stress response mechanisms, providing positive effects on development and yield. The overexpression of phyA in rice (Oryza sativa) resulted in reduced plant height and number of tillers, greater grain size and increased yield (Kong et al., 2004). However, not all attempts to overexpress phytochrome genes have changed plant architecture (Clough et al., 1995). Moreover, the increase in expression of LrCYP in glyphosate-susceptible and glyphosate-resistant biotypes under interspecific competition can be considered a defense mechanism against stress. The cytochrome P450 enzymes have an important role in the primary and secondary metabolism in plants by cleaving molecular oxygen to produce water (Bak et al., 2011).

The effects of competition during the initial development in soybean can be modified by row spacing, population and weed infestation due to a broad phenotypic plasticity, which is considered a key-point for competition in the field (VilaAiub et al., 2015). In soybean, the competition with weeds at early development stages can cause differential expression to oxidative gene stress and changes in the photosynthesis rate (Horvath et al., 2015). In weeds, the absence of fitness/adaptive costs in several herbicide-resistant biotypes, when subjected to other stresses, is considered a significant advantage for the succession process that reduces crop yields. Thus, the effects of competition at the molecular level can be different due to polygenic regulation in both crops and weed and, considering the first study reporting the involvement of genes of antioxidative enzymes and the photosynthetic apparatus in soybean and Italian ryegrass under competition. Gene mechanisms can then be used to develop a more holistic strategy for applying weed management tools.

\section{Materials and methods}

\section{Plant materials and experimental conditions}

The experiment was conducted in a greenhouse using a randomized block design, with four replications. The soybean (cultivar NA 5909RR), the glyphosate-susceptible (SVA02) and the resistant (SVA04) Italian ryegrass biotypes obtained from São Valentin-RS $\left(27.50^{\circ} \mathrm{S}\right.$ and $\left.54.18^{\circ} \mathrm{W}\right)$ (Vargas et al., 2016) were allocated in replacement series with 24 plants per pot in ratios of 100:0 (24 soybean plants), 50:50 (12 soybean and 12 Italian ryegrass plants) and 0:100 (24 Italian rygrass plants). The plants were sown in plastic pots with five liters of volumetric capacity and $20 \mathrm{~cm}$ of diameter, containing Red-yellow Argisol belonging to the Pelotas mapping unit. Soybean sowing was carried out 20 days after the emergence of the Italian ryegrass, to simulate the escape or regrowth of plants which occurs in fields after herbicide spraying in pre-sowing. The leaf samples were harvested at 50 days after emergence of the soybean crop from young leaves (pool of last trifoliate leaves or last tillers), and were stored in an ultralow-temperature freezer at $-80^{\circ} \mathrm{C}$ for RNA extraction.

\section{Total RNA isolation and cDNA synthesis}

Total RNA was extracted from leaf tissue using the PureLinK ${ }^{T M}$ reagent (Plant RNA Reagent - Invitrogen ${ }^{T M}$ ), as recommended by the manufacturer, followed by digestion with DNAse $\mathrm{I}^{\mathrm{TM}}$ (Invitrogen ${ }^{\mathrm{TM}}$ ). cDNA was synthesized using the SuperScript ${ }^{T M}$ III First-Strand Synthesis System for RTqPCR (Invitrogen ${ }^{T M}$ ), according to recommendations. The integrity of the RNAs was evaluated through agarose gel electrophoresis at $1 \%(p / v)$ while quantity and purity were determined using the NanoDropTM 2000 spectrophotometer (Thermo Scientific).

\section{Primer design and RT-qPCR conditions}

Nine candidate genes were evaluated for each species, for soybean the genes were: actin2/7 (ACT2/7), actin 11 (ACT11), eukariotic elongation factor 1 beta (ELF1B), ask interacting protein 16 (SKIP16), metalloprotease insulin degrading enzyme (MTP), F-box family protein (F-box), 60S ribossomal protein (60S), alpha tubulin 5 (TUA5) and beta tubulin 4 (TUB4); and for the Italian ryegrass: $18 \mathrm{~S}$ ribossomal protein $(18 \mathrm{~s})$, actin $(A C T)$, histone 2A (HIST), glyceraldehyde 3-phosphate dehydrogenase (GAPDH), cyclophilin (Cyclo), 605 ribossomal protein (60S), ADP-ribosylation factor $(A D P)$, cell division control protein (CDCP), alpha tubulin 5 (TUA5) and eukariotic elongation factor 1 alpha $(e E F 1 A(s))$, which were previously reported as candidates in other studies (Table 1).

The RT-qPCR technique was applied using the LightCycler 480 Instrument II (96) ${ }^{\mathrm{TM}}$ platform (Roche Applied Science ${ }^{T M}$ ) using the $S Y B R^{\circ}$ Green and three replicates for each CDNA sample. Amplification was achieved in a total volume of $12 \mu \mathrm{L}$ containing $6.25 \mu \mathrm{L}$ of LightCycler 480 SYBR Green I Master (Roche Applied Science), $0.5 \mu \mathrm{M}$ of primers $(10 \mathrm{mM})$, $1 \mu \mathrm{L}$ of cDNA $(0.2 \mu \mathrm{g})$ and ultrapure water until reaching the final volume. RT-qPCR parameters were a denaturation cycle at $95 \circ \mathrm{C}$ for $5 \mathrm{~min}$, followed by 45 cycles at $95 \circ \mathrm{C}$ for $20 \mathrm{~s}$, $60 \circ \mathrm{C}$ for $15 \mathrm{~s}$ and $72 \circ \mathrm{C}$ for $20 \mathrm{~s}$, terminated by the dissociation curve with denaturation at $95 \circ \mathrm{C}$ for $5 \mathrm{~s}$, cooling at $70 \circ \mathrm{C}$ for $1 \mathrm{~min}$, gradual warming at $0.11^{\circ} \mathrm{C}$ until $95 \circ \mathrm{C}$ and cooling at 40 으 for 30s, using the LightCycler 480 system (Roche Applied Science). Amplicon purity was verified by the absence of dimers with primers or of unspecific amplicons which are detected by the presence of a single peak on the RT-qPCR melting curve and a single band with the expected size in agarose gel electrophoresis (2\%). PCR efficiency was obtained from four serial dilutions of $\operatorname{cDNA}(1: 1,1: 5,1: 25$ and $1: 125)$ to generate the standard slope in each pair of primers tested. $\mathrm{E}$ value was estimated by the equation $\mathrm{E}=$ $10^{-1 / \text { slope }}$ (Rasmussen, 2001) and values between 1.8 and 2.2 were considered acceptable for the reference genes.

\section{Selection of reference genes for RT-qPCR}

The amplification efficiency of reference primers was calculated individually from the logarithm (Log) of cDNA dilutions for soybean and Italian ryegrass (Table 2). Based on $C T$ values of each reaction, the $\Delta \Delta C T$ was calculated using the expression $Q R=2^{-\Delta \Delta C T}$, in which $Q R$ represents the gene expression level and $\mathrm{CT}$ the exponential amplification cycle for each sample, using the difference between $\Delta \mathrm{CT}$ of the sample of interest and the reference of sample control (Livak and Schmittgen, 2001).

\section{Statistical analysis}

The expression level of all reference genes were measured by the $\mathrm{Ct}$ value, which is the number of PCR cycles needed to reach a specific threshold level of detection and is inversely correlated with the quantity of initial RNA template. For RTqPCR normalization, a moderately expressed reference gene is preferred because extremely high or low expression could introduce variability into the data analysis (Tan et al., 2011). 
The selection of reference genes was done through geNorm, NormFinder and BestKeeper software and by the $\Delta \mathrm{Ct}$ comparative method used to estimate the stable gene for normalization. These analyses demonstrate a ranking of less stable genes measured by stability (M) and normalization factors $\left(V_{n / n+1}\right.$ value), which allow for the analysis of relative expression patterns of target genes (Chen et al., 2011). Genes were considered less stable when the $M$ value and normalization factors were lower than 1.5 and 0.15 , respectively ( $\mathrm{Ma}$ et al., 2013). The BestKeeper software logarithm was used to calculate the standard deviation (cutoff point where $S D \geq 1$ value). The values of relative quantification were submitted to ANOVA, and means were compared by Tukey test $(p \leq 0.05)$.

\section{Conclusion}

SKIP and GAPDH genes were the most stable for the normalization of gene expression in Roundup Ready soybean and glyphosate-susceptible and resistant biotypes of Italian ryegrass under inter and intraspecific competition. RT-qPCR allowed us to analyze the differential expression genes responsible for antioxidative enzymes and the photosynthetic apparatus genes in response to inter and intraspecific competition. This information provides an opportunity to investigate more deeply key issues in weed science.

\section{Acknowledgements}

The first author thanks for the financial support provided by CAPES/FAPERGS ( $n^{\circ}$ 09/2012). We are grateful to Gustavo Zimmer for help in the check-in of the written.

\section{References}

Andersen CL, Jensen JL, Orntoft TF (2004) Normalization of real-time quantitative reverse transcription-PCR data: a model-based variance estimation approach to identify genes suited for normalization, applied to bladder and colon cancer data sets. Cancer Res. 64:5245-5250.

Badawi GH, Yamauchi Y, Shimada E, Sasaki R, Kawano N, Tanaka K (2004) Enhanced tolerance to salt stress and water deficit by overexpressing superoxide dismutase in tobacco (Nicotiana tabacum) chloroplasts. Plant Sci. 66: 919-28.

Bak S, Beisson F, Bishop G, Hamberger B, Höfer R, Paquette S, Werck-Reichhart D (2011) Cytochromes P450. Arabidopsis Book. 9:1-56.

Ballaré CL (2014) Light regulation of plant defense. Ann Rev Plant Biol. 65:335-363.

Benemann DP, Nohatto AM, Vargas L, Avila LA, Agostinetto $D$ (2017) Identification and validation of reference genes for the normalization in real-time RT-qPCR on rice and red rice in competition, under different nitrogen doses. Planta Daninha. 35:e017161319.

Bhatt I, Tripathi BN (2011) Plantperoxiredoxins: catalytic mechanisms, functional significance and future perspectives. Biotechnol Advances. 29:850-859.

Bustin SA (2002) Quantification of mRNA using real time reverse transcription PCR (RT-PCR): Trends and problems. J Mol Endocrinol. 29:23-39.

Chen L, Zhong HY, Kuang JF, Li JG, Lu WJ, Chen JY (2011) Validation of reference genes for RT-qPCR studies of gene expression in banana fruit under different experimental conditions. Planta. 234:377-390.
Crismani W, Baumann U, Sutton T, Shirley N, Webster T, Spangen- Berg G, Langridge P, Able JA (2006) Microarray expression analysis of meiosis and microsporogenesis in hexaploid bread wheat. BMC Genomics. 7:267.

Chi X, Hu R, Yang Q, Zhang X, Pan L, Chen N, Chen M, Yang $Z$, Wang T, He Y, Yu S (2012) Validation of reference genes for gene expression studies in peanut by quantitative realtime RT-PCR. Mol Genet Genomics. 287:167-176.

Choudhury FK, Rivero RM, Blumwald E, Mittler R (2017) Reactive oxygen species, abiotic stress and stress combination. Plant J. 90:856-867.

Clarke B, Rahman S (2005) A microarray analysis of wheat grain hardness. Theor Appl Genet. 110: 1259-1267.

Clough RC, Casal JJ, Jordan ET, Christou P, Vierstra RD (1995) Expression of functional oat phytochrome $A$ in transgenic rice. Plant Physiol. 109:1039-1045.

Duke S (2015) Perspectives on transgenic, herbicideresistant crops in the USA almost 20 years after introduction. Pest Manag Sci. 71:652-657.

Feng CH, Qui Y, Van Buskirk EK, Yang EJ, Chen M (2014) Light-regulated gene repositioning in Arabidopsis. Nature Commun. 5:3027.

Feng J, Li J, Gao Z, Lu Y, Yu J, Zheng Q, Yan S, Zhang W, He H, Ma L, Zhu Z (2015) SKIP confers osmotic tolerance during salt stress by controlling alternative gene splicing in Arabidopsis. Mol Plant. 8:1038-1052.

Horvath DP, Hansen SA, Moriles-Miller JP, Pierik R, Yan C, Clay DE, Scheffler B, Clay SA (2015) RNAseq reveals weedinduced PIF3-like as a candidate target to manipulate weed stress response in soybean. New Phytol. 207:196210.

Huang L, Yan H, Jiang X, Yin G, Zhang X, Qi X, Zhang Y, Yan Y, Ma $X$, Peng $Y$ (2014) Identification of candidate reference genes in perennial ryegrass for quantitative RT-PCR under various abiotic stress conditions. PLoS ONE. 9:e93724.

Hu R, Fan C, Li H, Zhang Q, Fu FY (2009) Evaluation of putative reference genes for gene expression normalization in soybean by quantitative real-time RT-PCR. BMC Mol Biol. 10:93.

Jansson S (1994) The light-harvesting chlorophyll a/bbinding proteins. Biochim Biophys Acta. 1184:1-19.

Jian B, Liu B, Bi Y, Hou W, Wu C, Han T (2008) Validation of internal control for gene expression study in soybean by quantitative real-time PCR. BMC Mol Biol. 9:59.

Kong SG, Lee DS, Kwak SN, Kim JK, Sohn JK, Kim IS (2004) Characterization of sunlight-grown transgenic rice plants expressing Arabidopsis phytochrome A. Mol Breed. 14:3545.

Le TD, Aldrich DL, Valliyodan B, Watanabe $\mathrm{Y}, \mathrm{Ha} \mathrm{CV}$, Nishiyama R, Guttikonda SK, Quach TN, Gutierrez-Gonzalez JJ, Tran LSP, Nguyen HT (2012) Evaluation of candidate reference genes for normalization of quantitative RT-PCR in soybean tissues under various abiotic stress conditions. PLoS ONE. 7:e46487.

Lee JM, Roche JR, Donaghy DJ, Thrush A, Sathish P (2010) Validation of reference genes for quantitative RT- PCR studies of gene expression in perennial ryegrass (Lolium perenne L.). BMC Mol Biol. 11:8.

Li SM, Bao-Zhen LI, Wei-Ming S (2012) Expression patterns of nine ammonium transporters in rice in response to $n$ status. Pedosphere. 22:860-869.

Livak KJ, Schmittgen TD (2001) Analysis of relative gene expression data using real-time quantitative PCR and the 2 ${ }_{\Delta \Delta C T}$ method. Methods. 25:402-408.

Ma S, Niu H, Liu C, Zhang J, Hou C, Wang D (2013) Expression stabilities of candidate reference genes for RT-qPCR under 
different stress conditions in soybean. PLoS ONE. 8:e75271.

Mhadhbi H, Fotopoulos V, Mylona PV, Jebara M, Aouani ME, Polidoros NA (2011) Antiox- idant gene-enzyme responses in Medicago truncatula genotypes with different degree of sensitivity to salinity. Physiol Plant. 141:201-14.

Mazza CA, Ballaré CL (2015) Photoreceptors UVR8 and phytochrome $B$ cooperate to optimize plant growth and defense in patchy canopies. New Phytol. 207:4-9.

Mckenzie-Gopsill AG, Lee E, Lukens L, Swanton CJ (2016) Rapid and early changes in morphology and gene expression in soya bean seedlings emerging in the presence of neighbouring weeds. Weed Res. 56:267-273.

Mittler R (2017) ROS are good. Trends Plant Sci. 22:11-19.

Mohammadi M, Kav NNV, Deyholos MK (2007) Transcriptional profiling of hexaploid wheat (Triticum aestivum L.) roots identifies novel, dehydration-responsive genes. Plant, Cell Environ. 30:630-645.

Nohatto MA, Benemann DP, Oliveira C, Vargas L, Avila LA, Agostinetto D (2016) Expression of genes in cultivated rice and weedy rice in competition. Aust J Crop Sci. 10:749-757

Page ER, Tollenaar M, Lee EA, Lukens L, Swanton CJ (2010) Shade avoidance: an integral component of crop-weed competition. Weed Res. 50:281-288.

Paolacci AR, Tanzarella OA, Porceddu E, Ciaffi M (2009) Identification and validation of reference genes for quantitative RT-PCR normalization in wheat BMC Mol Biol. 10:11.

Rasmussen RP (2001) Quantification on the Light Cycler. In: Meuer S, Wittwer CT, Nakagawara K (eds) Rapid cycle Real-time PCR, methods and applications. 1ed. Heidelberg: Springer Press, 21-34.

Ricce WS, Alves SJ, Prete CEC (2011) Época de dessecação de pastagem de inverno e produtividade de grãos de soja. Pesq Agropec Bras. 46:1220-1225.

Steinrücken HC, Amrhein N (1980) The herbicide glyphosate is a potent inhibitor of 5-enolpyruvylshikimic acid-3phosphate synthase. Biochem Biophy Res Commun. 94:1207-1212.

Swanton CJ, Nkoa R, Blackshaw RE (2015) Experimental methods for crop-weed competition studies. Weed Sci. spe:2-11.

Tan SC, Carr CA, Yeoh KK, Schofield CJ, Davies KE, Clarke K (2011) Identification of valid housekeeping genes for quantitative RT-PCR analysis of cardiosphere-derived cells preconditioned under hypoxia or with prolyl-4hydroxylase inhibitors. Mol Biol Rep 39: 4857-4867.
Tseng MJ, Liu C, Yiu J (2007) Enhanced tolerance to sulfur dioxide and salt stress of transgenic Chinese cabbage plants expressing both superoxide dismutase and catalase in chloroplasts. Plant Physiol Biochem. 45:1-12.

Vandesompele J, De Preter K, Pattyn F, Poppe B, Van Roy N, De Paepe A, Speleman F (2002) Accurate normalization of real-time quantitative RT-PCR data by geometric averaging of multiple internal control genes. Genome Biol. 3:1-12.

Vargas L, Ruchel $Q$, Agostinetto D, Lamego FP, Langaro AC, Piesanti SR (2016) Verification of the mechanism of glyphosate resistance in Italian ryegrass biotypes. Planta Daninha. 34:565-573.

Vargas L, Roman ES (2005) Seletividade e eficiência de herbicidas em cereais de inverno. Rev Bras Herb. 4:1-10.

Vila-Aiub MM, Gundel PE, Preston C (2015) Experimental methods for estimation of plant fitness costs associated with herbicide-resistance genes. Weed Sci. 63:203-216.

Wan H, Sui Y, Malik AA, Chen J (2010) Selection of appropriate reference genes for gene expression studies by quantitative real-time polymerase chain reaction in cucumber. Anal Biochem. 399:257-261.

Wang $X$, Xie $Q$, Wang $H$, Wang $Y$, Yue $Y$, Gahura O, Ma S, Liu L, Cao Y, Jiao Y, Puta F, McClung CR, Xu X, Ma L (2012) SKIP is a component of the spliceosome linking alternative splicing and the circadian clock in Arabidopsis. Plant Cell. 24:3278-95.

Yang Q, Yin J, Li G, Qi L, Yang F, Wang R, Li G (2014) Reference gene selection for qRT-PCR in Caragana korshinskii Kom. under different stress conditions. Mol Biol Rep. 41:2325-2334.

Zaefyzadeh M, Quliyev RA, Babayeva SM, Abbasov MA (2009) The effect of the interaction between genotypes and drought stress on the superoxide dismutase and chlorophyll content in durum wheat landraces. Turk J Biol. 33:1-7.

Zeng L, Deng R, Guo Z, Yang S, Deng X (2016) Genome-wide identification and characterization of Glyceraldehyde-3phosphate dehydrogenase genes family in wheat (Triticum aestivum). BMC Genomics. 17.240.

Zhang Z, Hu J (2009) Development and validation of endogenous reference genes for expression profiling of Medaka (Oryzias latipes) exposed to endocrine disrupting chemicals by quantitative real-time RT-PCR. Toxicol Sci. 95:356-368. 